\title{
AGE-RAGE Stress in the Pathophysiology of Atrial Fibrillation and Its Treatment
}

\author{
Kailash Prasad, BSc (Distinction), MBBS (Hons), MD, PhD, DSc, FRCPC, FACC, FIACS, FICA ${ }^{1}$ \\ ${ }^{1}$ Department of Anatomy, Physiology and Pharmacology, College of \\ Medicine, University of Saskatchewan, Saskatchewan, Saskatoon, \\ Canada \\ Address for correspondence Kailash Prasad, MBBS (Hons), MD, PhD, \\ DSc, Department of Anatomy, Physiology and Pharmacology, College \\ of Medicine, University of Saskatchewan, 107 Wiggins Road, \\ Saskatoon, SK S7N 5E5, Canada (e-mail: k.prasad@usask.ca).
} Int J Angiol 2020;29:72-80.

\begin{abstract}
Keywords

- advanced glycation end products

- cell receptor for age

- soluble RAGE

- atrial fibrillation

- atrial structural remodeling

- atrial electrical remodeling

- treatment modalities

Atrial fibrillation (AF) is the most common of cardiac arrhythmias. Mechanisms such as atrial structural remodeling and electrical remodeling have been implicated in the pathogenesis of AF. The data to date suggest that advanced glycation end products (AGEs) and its cell receptor RAGE (receptor for AGE) and soluble receptor (sRAGE) are involved in the pathogenesis of AF. This review focuses on the role of AGE-RAGE axis in the pathogenesis of AF. Interaction of AGE with RAGE generates reactive oxygen species, cytokines, and vascular cell adhesion molecules. SRAGE is a cytoprotective agent. The data show that serum levels of AGE and sRAGE, and expression of RAGE, are elevated in AF patients. Elevated levels of sRAGE did not protect the development of AF. This might be due to greater elevation of AGE than sRAGE. Measurement of AGE-RAGE stress (AGE/sRAGE) would be appropriate as compared with measurement of AGE or RAGE or sRAGE alone in AF patients. AGE and its interaction with RAGE can induce AF through alteration in cellular protein and extracellular matrix. AGE and its interaction with RAGE induce atrial structural and electrical remodeling. The treatment strategy should be directed toward reduction in AGE levels, suppression of RAGE expression, blocking of binding of AGE to RAGE, and elevation of sRAGE and antioxidants. In conclusion, AGE-RAGE axis is involved in the development of AF through atrial structural and electrical remodeling. The treatment modalities for AF should include lowering of AGE, suppression of RAGE, elevation of sRAGE, and use of antioxidants.
\end{abstract}

Atrial fibrillation (AF) is the most common sustained clinical cardiac arrhythmia. ${ }^{1}$ Some people with AF have no symptoms and are observed during physical examination. Individuals with AF may have palpitation, irregular heartbeat, weakness, lightheadedness, fatigue, shortness of breath, chest pain, and dizziness. AF itself usually is not life threatening but is a serious condition and may contribute to morbidity and mortality. AF is a risk factor for heart failure, thromboembolism, hospitalization, morbidity, and death. Besides those problems, AF has socioeconomic consequences. Untreated AF increases the risk of stroke, heart failure, systemic embolism, increased mortality due to altered hemodynamics, atrial and ventricular dyssynchrony, and progressive atrial and ventricular mechanical dysfunction. Various mechanisms have been proposed for AF, including remodeling of atrium due to changes in atrial structure and function ${ }^{2-4}$ and electrophysiologic mechanisms. Advanced glycation end products (AGE)-receptor for AGE (RAGE) axis has been implicated in numerous diseases, including myocardial infaction, ${ }^{5}$ hyperthyroidism, ${ }^{6}$ and pulmonary hypertension. ${ }^{7}$ Recently, AGE-RAGE axis has been implicated in the development of $\mathrm{AF}^{1,8}$ This article provides a brief review of epidemiology, association of AF with some cardiovascular complications, pathophysiology and mechanisms of AF, AGE-RAGE axis, role of AGE-RAGE axis in the induction of $A F$, and possible therapeutic measures for the treatment of AF. published online

December 9, 2019
Copyright $\odot 2020$ by Thieme Medical Publishers, Inc., 333 Seventh Avenue, New York, NY 10001, USA. Tel: +1(212) 760-0888.
DOI https://doi.org/ 10.1055/s-0039-3400541. ISSN 1061-1711. 


\section{Epidemiology}

Annual incidence rate of AF vary depending on the studied population (0.8-28.3 cases/1,000 person-years $)^{8}$ and incidence density rate over time was $27.3 / 1,000$ life-years in 1993 compared with 28.3/1,000 life-years in $2007 .{ }^{9}$ Incidence of AF in the United States and Canada is 4.5\%/year with lifetime risk of $25 \%$ in individuals aged $\geq 40$ years. ${ }^{10}$ The incidence rate varies with geographical regions, the lowest incidence rates were $33.8 / 100,000$ person-year in male, and $19.8 / 100,000$ person-year in female in Asia Pacific region in 2010. The incidence was highest in North America (264.5/ 100,000 person-year in male population and $196.3 / 100,000$ person-year in female population). The overall prevalence of AF has been reported to be 1 to $2 \%$ in general population. ${ }^{9}$ The global prevalence rates of AF in 2010 in men and women were, respectively, 596.2/100,000 and 373.1/100,000 population. ${ }^{11}$ There is a regional variation in prevalence rate, the highest being in North America (925.7/100,000 population for males and 520.8/100,000 population for females) and the lowest prevalence rates were in Asia Pacific region (340.2/ 100,000 population for male and $196.0 / 100,000$ population for female). ${ }^{11}$ These authors also reported that the prevalence and incidence of AF increase with age. The projected prevalence of $\mathrm{AF}$ in the United States in 2050 will increase from 5.6 million (excluding paroxysmal and silent) to 12.1 to 15.9 million. ${ }^{12,13}$ Prevalence of AF in Canada and the United States is 700 to $775 / 100,000$ persons. ${ }^{11}$

\section{Classification of Atrial Fibrillation}

$\mathrm{AF}$ is classified into four groups:

1. Paroxysmal AF: AF episode comes and goes, and terminates spontaneously within 7 days, normally within 24 hours.

2. Persistent AF: AF episode lasts longer than 7 days and usually treatment is required.

3. Long-lasting AF: AF episode lasts longer than 12 months. Restoration to normal rhythm may be attempted but less effective.

4. Permanent AF: AF episode lasts longer than 1 year despite treatment. Rate control strategy therapy should be adopted.

\section{Possible Causes of Atrial Fibrillation}

Possible common causes of AF are hypertension, congestive heart failure, coronary artery disease, coronary artery bypass surgery, and valvular damage due to disease. ${ }^{14} \mathrm{Age}$ is a major risk factor. ${ }^{15}$ Other less common factors are cardiomyopathy, myocarditis, hyperthyroidism, ${ }^{16}$ sleep apnea, ${ }^{17}$ pulmonary embolism, atrial septal defect, heavy alcohol use, caffeine, tobacco, congenital heart disease, diabetes, chronic renal disease, sick sinus syndrome, obesity, viral infection, surgical stress, pneumonia, genetic, and lone AF which occurs without any heart disease. ${ }^{18}$ Over $70 \%$ of AF is associated with heart disease. There is an association of hypertension $(140 / 90 \mathrm{~mm} \mathrm{Hg})$ and $\mathrm{AF}^{19}$ but the risk increase is modest (1.2-1.5). Hypertension is responsible for $14 \%$ of all cases of $\mathrm{AF}^{20}$ The systolic arterial pressure of 130 to $139 \mathrm{~mm} \mathrm{Hg}$ and increase in pulse pressure are risk of $\mathrm{AF}^{21}$ Genetic factor is also involved in $\mathrm{AF}^{22} \mathrm{AF}$ is associated with three- to fivefold increase in risk of ischemic stroke. ${ }^{23,24}$

\section{Pathogenesis of Atrial Fibrillation}

The pathogenesis of AF is complex and varies with individuals. ${ }^{25}$ Mechanisms including atrial structural remodeling, electrical remodeling, autonomic remodeling, and epicardial adipose tissue have been implicated in the development of AF. In this review, however, stress will be given to atrial structural remodeling and electrical remodeling. This will help in understanding the role of AGE-RAGE axis in the development of AF.

\section{Atrial Structural Remodeling}

Evidence indicates that structural remodeling particularly interstitial fibrosis is an important contributor to $\mathrm{AF}^{2}$ Profibrotic agents include proinflammatory cytokines, oxidative stress, transforming growth factor- $\beta_{1}$ (TGF- $\left.\beta_{1}\right)$, connective tissue growth factor (CTGF), platelet-derived growth factor (PDGF), renin-angiotensin-aldosterone system, extracellular matrix (ECM) regulatory proteins, and hypoxia-inducible factor- $1 \alpha$ and endothelin- 1 system, ${ }^{25-27}$ and act synergistically. CTGF is also known as insulin-like growth factor binding protein-related protein-2 (TGFBR-rP $\mathrm{P}_{2}$ ). CTGF, a cytokine, is a potent inducer of ECM. ${ }^{28}$ In vitro studies have been shown that there is an increase in both CTGF gene and protein expression in mesangial cells after exposure to high glucose, and in vitro studies assessing CTGF expression in diabetic rat kidney. ${ }^{29}$ Secretome from human epicardial fat tissue of patients undergoing routine cardiac bypass surgery is known to induce fibrosis through release of adipo-fibrokine activin $\mathrm{A}$ in an organo culture of rat atria. ${ }^{30}$ There are two types of fibrosis, interstitial and reparative. Interstitial fibrosis separates muscle bundles and reparative fibrosis replaces dead cardiomyocytes which interferes with electrical continuity and slows the conduction. ${ }^{2,31}$ Fibroblasts couple electrically with cardiomyocytes and may promote reentry and/or ectopic activity when in large number. ${ }^{32}$ Fibroblasts ion channel may be used for suppressing arrhythmias caused by fibroblast-cardiomyocyte electric interactions and through inhibition of collagen formation. ${ }^{32}$ Fibrosis leads to progression of $\mathrm{AF}$ to permanent form of $\mathrm{AF}^{31,33}$ Studies suggest that atrial fibrosis can be reduced with inhibition of angiotensin-renin-aldosterone system, ${ }^{34}$ and simvastatin. ${ }^{35}$ Studies have also shown that reversal of risk factor for AF can reduce the atrial fibrosis. ${ }^{36,37}$

AF is associated with increased atrial fibrosis. ${ }^{3,4}$ Remodeling of atrium due to changes in atrial structure and function can generate AF. Rapid ectopic firing and reentry maintains AF. Atrial remodeling can produce unidirectional block and slow conduction. Atrial remodeling can create after local differences in membrane potential due to differences in repolarization of action potential and reentrant excitation in region of conduction delay and unidirectional block. Unidirectional block is a common cause of coupled extrasystole and a variety of sustained ectopic beats, flutter, and fibrillation. Factors that favor reentrant type of 
arrhythmias are long pathway due to local block, cardiac cells with short refractory period, and slow conduction.

\section{Electrical Remodeling}

Risk of AF is increased 3.5-fold in patients with coronary artery disease. ${ }^{38}$ Foci of rapid ectopic activity are located at the junction of atrium and pulmonary veins in human. ${ }^{39}$ Atrial action potential is not the same as action potential of ventricular cells. Gelband et al ${ }^{40}$ have identified two types of action potential in right atrial tissue of human: electrical characteristics of atrial contractile cells and fibers where automaticity develops. Prasad ${ }^{41}$ reported that the action potential in the human atrial tissue had also two types of action potentials: pacemaker type of action potential with two humps in the plateau phase observed in spontaneously beating atria and associated with triple contraction, and a nonpacemaker type of action potential in quiescent fiber stimulated electrically. There are three mechanisms of ectopic beats: diastolic depolarization, early afterdepolarization (EAD), and delayed afterdepolarization (DAD). ${ }^{26}$ Increased diastolic depolarization creates automatic activity (ectopic beat). EAD occurs during repolarization phase when the action potential duration (APD) is prolonged. Occurrence of EAD increases the prevalence of AF in congenital long QT syndrome. ${ }^{42}$ EAD in prolonged APD allows L-type $\mathrm{Ca}^{2+}$ to recover from inactivation resulting in depolarizing inward movement of $\mathrm{Ca}^{2+}$ ions. ${ }^{43}$ DAD is due to abnormal diastolic release of $\mathrm{Ca}^{2+}$ from sarcoplasmic reticulum. ${ }^{44}$ EAD cells close to normally repolarizing cells raise the normally repolarizing cells to threshold to fire and initiate focal activity. ${ }^{45}$

Reentrant excitation is a common cause of coupled extrasystole as well as a variety of sustained ectopic rhythm, flutter, and fibrillation. Factors that favor reentrant arrhythmias are (1) long pathway due to local block, (2) cardiac cells with short refractory period, and (3) slow conduction. Early capture of excitability due to decrease in the refractory period as a result of decrease in APD leads to sustained re-entrant impulses throughout the circuit. Slow conduction would allow the impulse to reenter without short refractory period. Atrial structural changes such as dilation and fibrosis increase pathway and slow conduction that would favor reentrant arrhythmias. $^{33}$

\section{AGE-RAGE Axis}

Advanced glycation end products are heterogeneous groups of irreversible adducts formed by nonenzymatic glycation of proteins, lipids, and nucleic acids with reducing sugars. ${ }^{46,47}$ Physiologically, this process occurs at a low rate but is accelerated in hyperglycemia, inflammation, renal failure, Alzheimer's disease, and micro- and macrovascular disease. ${ }^{48,49}$ AGE has two potentially harmful effects. First, it forms cross-links with collagen and elastin, resulting in stiffness of the artery, ${ }^{50}$ and it upregulates CTGF. $^{29}$ Second, AGE interacts with its cell receptor (RAGE) to produce reactive oxygen species (ROS) through activation of nicotinamide adenine dinucleotide phosphate (NADPH) oxidase ${ }^{51}$ which activates nuclear factor-kappa B $(\mathrm{NF}-\mathrm{kB}){ }^{52}$ Activated NF-kB activates numerous genes such as tumor necrosis factor- $\alpha$ (TNF- $\alpha$ ), interleukin (IL)-1, IL-2, IL-6, IL-8, and IL-9. ${ }^{53,54}$ Proinflammatory cytokines upregulate NADPH oxidase $e^{55}$ and increase the generation of ROS. ${ }^{56}$ There are two isoforms of RAGE: cleaved RAGE (CRAGE), which is proteolytically cleaved from full-length RAGE, ${ }^{57}$ and endogenous secretory RAGE (esRAGE), which is produced from splicing of full-length RAGE mRNA. ${ }^{49}$ sRAGE is composed of both cRAGE and esRAGE. In healthy subjects, the levels of serum SRAGE are four to five times greater than the levels of serum CRAGE. ${ }^{58,59}$ Since the extracellular domain in SRAGE is maintained as RAGE, the ligand-binding capacity is similar to RAGE receptor. sRAGE, therefore, acts as a decoy for RAGE by binding with RAGE ligands. ${ }^{60}$ Binding of sRAGE with ligands does not activate intracellular signaling. sRAGE also is a competitive inhibitor of ligand-RAGE interaction. ${ }^{61}$ sRAGE has cytoprotective effects against adverse effects of AGE-RAGE interaction.

\section{Serum and Atrial Levels of AGE in AF}

Plasma levels of fluorescent AGE were significantly higher in patients with AF compared with control subjects $(74.9 \pm 25.6$ vs. $61.8 \pm 20.1$ a.u.). Raposeiras-Roubín et $\mathrm{al}^{8}$ also reported that the plasma levels of fluorescence AGE were higher in patients with AF than in patients with sinus rhythm in nondiabetic group $(72.3 \pm 25.2$ vs. $57.8 \pm 20.3$ a.u.). The fluorescence AGE levels were elevated in patients with chronic heart failure and AF. ${ }^{62}$ Patients with AF have elevated levels of AGE in atrial tissue and serum compared with those with sinus rhythm, and myocardial AGE levels were positively correlated with fibrosis. ${ }^{1,8}$ The data suggest that the levels of AGE in plasma and tissue are elevated in patients with AF.

\section{RAGE Levels in Atrium in AF}

Using immunostaining and Western blotting, the expression of RAGE protein in atria of diabetic rats has been shown to be elevated compared with control. ${ }^{63}$ They also reported that expression of CTGF immune-reactive protein was increased by threefold in atria of diabetic rats as compared with control nondiabetic rats. These investigators reported that streptozotocin-induced diabetic rats had diffuse interstitial fibrosis in atria. The inhibition of AGE formation with OPB9195 compound suppressed the diabetic-induced AF and reduced the expression of CTGF. Suppression of AGE with OPB-9195 would have reduced the interaction of RAGE with AGE and hence reduced the generation of proinflammatory cytokines, adhesion molecules, and chemokines resulting in reduced fibrosis and prevention of AF. The data indicate that expression of RAGE is elevated in diabetic rats with AF.

\section{Plasma/Serum Levels of sRAGE in AF}

Raposeiras-Roubín et $\mathrm{al}^{8}$ reported that patients with $\mathrm{AF}$ had higher plasma levels of sRAGE compared with control subjects $(1,714.2 \pm 1,105.5$ vs. $996.1 \pm 820.7 \mathrm{pg} / \mathrm{mL}, p=0.001)$. The plasma levels of sRAGE were higher in nondiabetic AF group compared with nondiabetic group with sinus rhythm $(1,614.7 \pm 1,068.5$ vs. $934.9 \pm 778.5 \mathrm{pg} / \mathrm{mL}, p=0.011)$ and 
AF with diabetes compared with sinus rhythm with diabetes $(1,897.8 \pm 1,192.4$ vs. $1,081.7 \pm 885.5, p=0.022)$. Serum sRAGE levels tended to be higher but not significantly in patients with $\mathrm{AF}$ than in patients without $\mathrm{AF}$ $(737.9 \pm 446.7 \mathrm{pg} / \mathrm{mL}$ vs. $624.0 \pm 443.5 \mathrm{pg} / \mathrm{mL}, p=0.254){ }^{64}$ Lancefield et al ${ }^{65}$ showed that sRAGE levels were higher in patients with persistent AF compared with paroxysmal AF (median: 1,196 [724-2,041] vs. 799 [583-1,033] pg/mL), and higher in persistent AF compared with sinus rhythm $(1,196$ [724-2,041] vs. 782 [576-1,039]). They also reported that serum sRAGE levels were elevated in Caucasian patients with persistent AF. SRAGE levels are elevated in patients with persistent AF compared with paroxysmal AF and compared with patients with sinus rhythm. ${ }^{66}$ However, Al Rifai et al ${ }^{67}$ reported that there was no significant association of sRAGE and risk of AF. Yang et al ${ }^{68}$ showed that high level of plasma sRAGE is independently associated with low recurrence of AF after catheter ablation in diabetic patients. These data suggest that the serum levels of sRAGE are higher in patients with AF as compared with individuals with sinus rhythm and that the elevation is higher in patients with persistent AF compared with patients with paroxysmal AF.

\section{esRAGE and CRAGE in AF}

It has been reported that cRAGE levels were higher in patients with persistent AF compared with patients with paroxysmal $\mathrm{AF}$ and the levels were higher in these two groups compared with controls (control, $480.8 \pm 214.3$; paroxysmal AF, 692.1 \pm 287.2 ; and persistent AF, $965.6 \pm$ $312.9 \mathrm{pg} / \mathrm{mL}) .{ }^{66}$ However, esRAGE levels were lower in both paroxysmal AF and persistent AF compared with control subjects $(286.7 \pm 161.4,170.4 \pm 113.9$, and $412.6 \pm 178.5 \mathrm{pg} / \mathrm{mL})$. The levels were lower in persistent AF patients than in paroxysmal AF group. ${ }^{66}$ Yan et al ${ }^{64}$ showed that esRAGE levels were lower in AF patients as compared with non-AF patients $(0.29 \pm 0.12$ vs. $0.34 \pm 0.15 \mathrm{ng} / \mathrm{mL} ; p=0.005)$. Chinese patients with persistent AF had lower levels of esRAGE compared with patients with paroxysmal AF. ${ }^{64,66}$ However, serum esRAGE levels were significantly elevated in Caucasian patients with persistent $A F^{65}$ Both serum sRAGE and esRAGE are associated with increased risk of persistent AF compared with paroxysmal AF. ${ }^{65}$ These data suggest that the serum levels of CRAGE are higher in both persistent and paroxysmal AF as compared with control subjects, and higher in patients with persistent AF compared with patients with paroxysmal AF. Plasma levels of esRAGE were lower in patients with AF compared with control subjects.

\section{Mechanism by which AGE and RAGE Stress Induces AF}

There are three ways by which AGE can induce AF: (1) alteration of cellular protein resulting in cellular function, (2) alteration in ECM (structural modification of atria), and (3) interaction of AGE with RAGE receptor resulting in ROS that activates NF-kB. ${ }^{52}$ Activated NF-kB activates numerous genes, such as TNF- $\alpha$, IL-1, IL-2, IL-6, IL-8. And
IL-9, ${ }^{53,54}$ as well as adhesion molecules. ${ }^{69}$ Proinflammatory cytokines upregulate NADPH oxidase ${ }^{55}$ and increase the generation of ROS. ${ }^{56}$ Thus, AGE may play a role in the pathophysiology of AF through the aforementioned mechanisms. The following section discusses the role of AGE and its interaction with RAGE-induced atrial structural and electrical remodeling in the pathophysiology of AF.

\section{Structural Remodeling of Atrium}

Structural remodeling is due to fibrosis. Both AGE and its interaction with RAGE take part in atrial fibrosis.

\section{AGE-Induced Structural Remodeling of Atrium}

Accumulation of AGE on protein of ECM forms cross-links. Cross-linking of AGE on collagen and elastin increases the ECM area. ${ }^{70}$ AGE promotes protein cross-linking that alters protein structure and function of collagen and elastin resulting in atrial fibrosis. ${ }^{71}$ Twigg et al ${ }^{29}$ reported that AGE upregulates CTGF, also known as insulin-like growth factor binding proteinrelated protein-2 (IGFBR-rP 2 ) and TGF- $\beta 1$ mRNA protein expression. CTGF is a potent inducer of ECM. ${ }^{72}$ AGE significantly increases the potent profibrotic growth factor, TGF- $\beta_{1} \cdot{ }^{73} \mathrm{CTGF}$ acts as a downstream mediator of TGF- $\beta_{1}$-induced fibrosis. ${ }^{74}$ Zhau et $\mathrm{al}^{75}$ reported that AGE-induced CTGF expression occurs predominantly through TGF- $\beta_{1}$-dependent pathway and plays a role in ECM deposition.

\section{AGE and RAGE Interaction-Induced Structural \\ Remodeling of Atrium}

AGE not only changes atrial structure and physiological function but also modulates inflammatory and fibrotic reactions through binding with RAGE receptor. As discussed earlier, interaction of AGE and RAGE produces ROS, proinflammatory cytokine, and cell adhesion molecules. Stimuli such as ROS, cytokines, adhesion molecules, and growth factor stimulate fibroblast proliferation, migration, and differentiation into myofibroblast. ${ }^{32}$ Myofibroblasts produce MMPs and ECM proteins. Increased ECM expression and activity increases extracellular deposition. ${ }^{76}$ TGF- $\beta$ stored in ECM is involved in the regulation of atrial fibrosis. ROS induces the CTGF. ${ }^{77}$ ROS activates TGF- $\beta$ which regulates NOX4 expression and NOX4-dependent generation of hydrogen peroxide. Hydrogen peroxide is required for TGF- $\beta$ induced myofibroblast differentiation and ECM production. ${ }^{78,79}$ TNF activates TGF- $\beta$ signaling pathway and myofibroblasts, and increases secretion of MMP-2 and MMP-9 which modulate atrial remodeling. ${ }^{80}$ sVCAM- 1 is associated with long-term risk of $\mathrm{AF}^{81}$ Verdejo et $\mathrm{al}^{82}$ reported that elevated sVCAM-1 predicts a higher risk of postoperative AF in patients undergoing coronary artery bypass surgery.

\section{Electrical Remodeling of Atrium}

\section{AGE and Electrical Remodeling}

Increased fibrosis due to elevated levels of AGE would induce electrical remodeling in atria leading to AF. It is supported by the fact that increased fibrosis promotes EAD and triggered activity at left atrial pulmonary vein junction. ${ }^{83}$ EAD could be 
due to increase in diastolic $\mathrm{Ca}^{2+} .{ }^{83}$ Mitochondria could be the other source of $\mathrm{Ca}^{2+} \cdot{ }^{84} \mathrm{AF}$ arising from structurally remodeled atria could be due to changes in the electrical properties of ECM. Fibrosis causes localized slowing of conduction and increasing conduction heterogeiety ${ }^{85}$ which may result in unidirectional block and macro-entry. ${ }^{86}$

\section{AGE-RAGE-Induced Inflammation and Electrical Remodeling}

As described earlier, interaction of AGE with RAGE generates ROS, inflammatory mediators, and PDGF. Inflammation, atrial fibrosis, and oxidative stress are important factors that initiate $\mathrm{AF}$.

ROS $\left(\mathrm{H}_{2} \mathrm{O}_{2}\right)$ prolongs APD and induces triggered activity via EAD and DAD. ROS directly stimulates L-type $\mathrm{Ca}^{2+}$ current, which results in abnormal intracellular $\mathrm{Ca}^{2+}$ cycling in myocytes and facilitates EAD. ${ }^{87} \mathrm{H}_{2} \mathrm{O}_{2}$-induced prolongation of APD and EAD is due to development of enhanced sodium current. ${ }^{88}$ Increase in late sodium current may result in arrhythmias via an EAD mechanism by ROS. ROS induces fibrosis in atria. ${ }^{32,76,77}$ ROS enhances fibroblast proliferation and collagen gene expression. ${ }^{89}$ Atrial fibrosis would promote EAD and triggered actvity ${ }^{83}$ and unidirectional block. ${ }^{86}$ TNF produces abnormal $\mathrm{Ca}^{2+}$ handling and arrhythmogeneity in pulmonary vein cardiomyocytes. ${ }^{90}$

Overexpression of TNF in cardiac tissue prolongs APD and $\mathrm{Ca}^{2+}$ transient duration. ${ }^{91}$ These investigators also reported that TNF directly alters $\mathrm{Ca}^{2+}$ handling in cardiomyocytes which is crucial for initiation of AF and atrial electrical modeling. PDGF from myofibroblasts reduces APD and $\mathrm{Ca}^{2+}$ transients. ${ }^{92}$ Inflammation increases the heterogeneity of conduction and AF duration. ${ }^{93}$ Heterogeneity of conduction could be due to altered expression or distribution of gap junction L-5 protein or atrial fibrosis. ${ }^{94}$

\section{Treatment Modalities for Atrial Fibrillation}

Aforementioned data suggest that AGE-RAGE stress is involved in the development of AF. The treatment strategy for AF, therefore, should be directed toward lowering of AGERAGE stress. AGE-RAGE stress reduction would prevent, regress, and slow the progression of AF. Three-pronged attack-reduction of AGE and expression RAGE levels, blocking of AGE binding to RAGE, and elevation of sRAGE levelsshould be attempted in the treatment of AF. Additionally, antioxidants and anti-inflammatory agents would be helpful in the treatment of AF. The details of reduction of AGE, and expression of RAGE, blockers of AGE binding to RAGE and elevation of sRAGE have been reported earlier by Prasad ${ }^{95}$ and Prasad and Mishra. ${ }^{96}$ Hence, only a summary of treatment modalities is provided later.

\section{Reduction in Levels of AGE}

Low levels of AGE in the body can be accomplished by reducing dietary consumption of AGE-rich diet, preventing AGE formation, using pharmaceutical agents, and increasing degradation of AGE. Reduction in consumption of high AGErich diet such as red meat, cheese, cream, butter, and animal fat should be advised. Consumption of food with lowest amount of AGE such as grains, legumes, breads, vegetable, fruits, and milk, especially fat-free milk, should be encouraged. Cooking at high temperature in dry heat for long period should be advised since it increases the formation of AGE. Frying, broiling, and roasting generate more AGE than poaching, stewing, steaming, and boiling. Cooking in moist heat at low temperature for short duration should, therefore, be advised. Cigarette smoking elevates serum levels of AGE and hence cigarette smoking should be completely stopped. Exercise should be advised and encouraged because exercise reduces the serum levels of AGE.

Consumption of acidic ingredients such as lemon and vinegar should be advised as they inhibit formation of AGE. Use of vitamins such as benfotiamine, pyridoxine, vitamin $\mathrm{B} 6$, vitamin $\mathrm{C}$, vitamin $\mathrm{D}$, and vitamin $\mathrm{E}$ should be advised as they inhibit the formation of AGE. Carnosine also inhibits AGE formation and hence its use can be advocated.

Angiotensin-converting enzyme inhibitors (ramipril), angiotensin II receptor blockers (telmisartan, losartan, valsartan, and candesartan), statins (cerivastatin, atorvastatin), and other drugs (pioglitazone, $\alpha$-lipoic acid, pentoxifylline, resveratrol, curcumin, and aspirin) reduce the levels of AGE in serum. Patients who are using one or more of these drugs will benefit.

\section{Suppression of RAGE Expression}

Agents such as simvastatin, atorvastatin, telmisartan, candesartan, thiazolidinediones, nifedipine, and curcumin downregulate the expression of RAGE.

\section{Blocking of Binding of AGE to RAGE}

Azeliragon prevents the binding of AGE to RAGE. ${ }^{97}$ In low dose, it has been shown to have some beneficial effects in patients with Alzheimer's disease. ${ }^{98}$ This drug has not been tried in any other disease. sRAGE is considered a blocking agent for RAGE as it competes with RAG to bind with AGE. Increases in the levels of sRAGE would reduce the levels of AGE to combine with RAGE. This would reduce the adverse effects of interaction of AGE with RAGE.

\section{Elevation of SRAGE}

Because sRAGE competes with RAGE for binding with AGE and since interaction of AGE with sRAGE does not activate intracellular signaling, elevation of SRAGE would benefit patients with AF. The levels of SRAGE can be elevated in two ways: use of pharmaceutical agents and exogenous administration of sRAGE. Statins (pitavastatin, pravastatin, atorvastatin, fluvastatin, and lovastatin), angiotensinconverting enzyme inhibitors (ramipril, perindopril), and antidiabetic drug (rosiglitazone) increase the sRAGE levels in serum and/or in isolated cell lines. Administration of sRAGE exogenously has been shown to suppress the development of atherosclerosis in apoE-deficient mice, ${ }^{99}$ carotid artery restenosis in mice, ${ }^{100}$ and AGE-induced vasculopathy in diabetic rats. ${ }^{101}$ sRAGE administration reduced the amyloid- $\beta$ levels ${ }^{102}$ and increased the capacity of space recognition, learning, and memory improvement ${ }^{103}$ in mouse with Alzheimer's disease. 


\section{Antioxidants}

Since AGE interacts with RAGE to generate ROS, ${ }^{51,56}$ which is involved in structural and electrical remodeling of $A F,{ }^{104}$ and antioxidant may serve as an additional option for the treatment of AF. Few studies have been performed with antioxidants in the treatment of AF. Vitamin E and vitamin C reduced the effective refractory period shortening, 105 while they had no effects in reducing atrial excitability or vulnerability ${ }^{106}$ to AF in animal model. Integrated use of Cordarone with antioxidants such as sodium bicarbonate and $\mathrm{Q}_{10}$ stabilized electrical process in heart of patients with AF. ${ }^{107}$ Long-term consumption of antioxidant-rich diet reduced the incidence of postoperative $\mathrm{AF}$ in patients undergoing cardiac surgery. ${ }^{108}$ Vitamins $C$ and $E$ have been effective as a prophylactic therapy to prevent postoperative AF. ${ }^{109-111}$ Review of literature by Rasoli et al ${ }^{112}$ has shown that vitamin $\mathrm{E}$ and vitamin $\mathrm{C}$ play a role in the prevention of AF both in animal and small clinical studies.

\section{Perspectives}

The data suggest that both AGE alone and its interaction with RAGE could induce AF. AGE induces atrial structural remodeling $^{70-73}$ and atrial electrical remodeling ${ }^{83-86}$ which have been suggested to be involved in the development of AF. Similarly, production of ROS, inflammatory cytokines, and cell adhesion molecules as a result of interaction of AGE with RAGE induce atrial structural remodeling ${ }^{76-82}$ and electrical remodeling. ${ }^{87-94}$ As described earlier, it is known that atrial structural and electrical remodeling are involved in the development of AF. These data suggest that AGE-RAGE axis in part is responsible for the development of AF. In all the aforementioned studies, AGE and sRAGE have been measured not in the same patients or animals. No consideration has been given for measurement of SRAGE which has a protective effect against adverse effects of AGE-RAGE interaction, and sRAGE is a RAGE blocking agent. Measuring AGE, SRAGE separately, is not useful because sRAGE is elevated along with AGE in patients with AF. May be the elevation of SRAGE is smaller than the elevation of AGE levels. For example, sRAGE and AGE levels are elevated in diabetes ${ }^{113,114}$ and end-stage renal disease, ${ }^{59}$ but the ratio of AGE/sRAGE is high in all these studies. It would be useful to measure AGE and sRAGE in the same patient because this will help in the assessment of AGE-RAGE stress which is measured as the ratio of AGE/sRAGE. ${ }^{115}$ This ratio is risk factor for disease and a high ratio indicates the presence of disease and its complications. ${ }^{115}$ The serum levels of sRAGE is elevated in patients with $\mathrm{AF}^{8,65}$ sRAGE should have protected from the development of AF but it did not. May be the elevation of AGE is greater than the elevation of sRAGE. It would be useful to measure both AGE and sRAGE in the same patient and use AGE-RAGE stress as a marker of AF.

Considering the involvement of AGE-RAGE axis in the pathogenesis of $A F$, the treatment modalities should include a reduction in the levels of AGE and RAGE, blockage of RAGE to bind with AGE, elevation of sRAGE, and use of antioxidants. As mentioned earlier in the section of antioxidants in the treat- ment of AF, antioxidants seem to have beneficial effects in the treatment of AF. However, systematic study should be performed with selected antioxidants (combination of vitamins $C$ and $\mathrm{E}$ in effective doses, melatonin). Combination of vitamins will be effective in two ways: by scavenging ROS and by reducing the formation of AGE. Studies should be designed to investigate if the agents prevent, regress, and slow the progression of AF. It is to note that AGE-RAGE axis may not be the only risk factor in the pathogenesis of AF. Therefore, one should not expect that AGE-RAGE targeted treatment would completely prevent, regress, and slow the progression of AF.

\section{Conclusions}

The data suggest that AGE-RAGE axis may be involved in the pathogenesis of AF through atrial structural and electrical remodeling. The treatment should be directed toward AGE, RAGE, and sRAGE, the three important components of AGERAGE axis. Three-pronged attack-reduction in AGE and RAGE levels, blocking of RAGE binding to AGE, and elevation of SRAGE-should be made in the treatment of AF. Additionally, antioxidants may also be beneficial in the treatment of AF.

\section{Disclosure \\ None.}

\section{Conflict of Interest}

None.

\section{Acknowledgment}

The author acknowledges the assistance of Dr. Kalpana Kalyanasundaram Bhanumathy in the submission of this manuscript to the journal.

\section{References}

1 Begieneman MP, Rijvers L, Kubat B, et al. Atrial fibrillation coincides with the advanced glycation end product $\mathrm{N}(\varepsilon)-($ carboxymethyl)lysine in the atrium. Am J Pathol 2015;185(08): 2096-2104

2 Burstein B, Nattel S. Atrial fibrosis: mechanisms and clinical relevance in atrial fibrillation. J Am Coll Cardiol 2008;51(08): 802-809

3 Boldt A, Wetzel U, Lauschke J, et al. Fibrosis in left atrial tissue of patients with atrial fibrillation with and without underlying mitral valve disease. Heart 2004;90(04):400-405

4 Geuzebroek GS, van Amersfoorth SC, Hoogendijk MG, et al. Increased amount of atrial fibrosis in patients with atrial fibrillation secondary to mitral valve disease. J Thorac Cardiovasc Surg 2012;144(02):327-333

5 McNair ED, Wells CR, Qureshi AM, et al. Low levels of soluble receptor for advanced glycation end products in non-ST elevation myocardial infarction patients. Int J Angiol 2009;18(04): 187-192

6 Caspar-Bell G, Dhar I, Prasad K. Advanced glycation end products (AGEs) and its receptors in the pathogenesis of hyperthyroidism. Mol Cell Biochem 2016;414(1-2):171-178

7 Prasad K. AGE-RAGE stress in the pathophysiology of pulmonary hypertension and its treatment. Int J Angiol 2019;28(02):71-79

8 Raposeiras-Roubín S, Rodiño-Janeiro BK, Grigorian-Shamagian L, et al. Evidence for a role of advanced glycation end products in atrial fibrillation. Int J Cardiol 2012;157(03):397-402 
9 Piccini JP, Hammill BG, Sinner MF, et al. Incidence and prevalence of atrial fibrillation and associated mortality among Medicare beneficiaries, 1993-2007. Circ Cardiovasc Qual Outcomes 2012;5 (01):85-93

10 Lloyd-Jones DM, Wang TJ, Leip EP, et al. Lifetime risk for development of atrial fibrillation: the Framingham Heart Study. Circulation 2004;110(09):1042-1046

11 Chugh SS, Havmoeller R, Narayanan K, et al. Worldwide epidemiology of atrial fibrillation: a Global Burden of Disease 2010 Study. Circulation 2014;129(08):837-847

12 Go AS, Hylek EM, Phillips KA, et al. Prevalence of diagnosed atrial fibrillation in adults: national implications for rhythm management and stroke prevention: the AnTicoagulation and Risk Factors in Atrial Fibrillation (ATRIA) Study. JAMA 2001;285 (18):2370-2375

13 Miyasaka Y, Barnes ME, Gersh BJ, et al. Secular trends in incidence of atrial fibrillation in Olmsted County, Minnesota, 1980 to 2000 , and implications on the projections for future prevalence. Circulation 2006;114(02):119-125

14 Allessie MA, Boyden PA, Camm AJ, et al. Pathophysiology and prevention of atrial fibrillation. Circulation 2001;103(05): 769-777

15 Nattel S. From guidelines to bench: implications of unresolved clinical issues for basic investigations of atrial fibrillation mechanisms. Can J Cardiol 2011;27(01):19-26

16 Auer J, Scheibner P, Mische T, Langsteger W, Eber O, Eber B. Subclinical hyperthyroidism as a risk factor for atrial fibrillation. Am Heart J 2001;142(05):838-842

17 Schoonderwoerd BA, Smit MD, Pen L, Van Gelder IC. New risk factors for atrial fibrillation: causes of 'not-so-lone atrial fibrillation'. Europace 2008;10(06):668-673

18 Atrial fibrillation: symptoms and causes. Available at: https:// www.mayoclinic.org/diseases-conditions/atrial-fibrillation/diagnosis-treatment/drc-20350630. Accessed October 15, 2019

19 Kannel WB, Abbott RD, Savage DD, McNamara PM. Epidemiologic features of chronic atrial fibrillation: the Framingham study. N Engl J Med 1982;306(17):1018-1022

20 Kannel WB, Wolf PA, Benjamin EJ, Levy D. Prevalence, incidence, prognosis, and predisposing conditions for atrial fibrillation: population-based estimates. Am J Cardiol 1998;82(8A):2N-9N

21 Mitchell GF, Vasan RS, Keyes MJ, et al. Pulse pressure and risk of new-onset atrial fibrillation. JAMA 2007;297(07):709-715

22 Mahida S, Lubitz SA, Rienstra M, Milan DJ, Ellinor PT. Monogenic atrial fibrillation as pathophysiological paradigms. Cardiovasc Res 2011;89(04):692-700

23 Healey JS, Connolly SJ, Gold MR, et al; ASSERT Investigators. Subclinical atrial fibrillation and the risk of stroke. N Engl J Med 2012;366(02):120-129

24 Rietbrock S, Heeley E, Plumb J, van Staa T. Chronic atrial fibrillation: Incidence, prevalence, and prediction of stroke using the Congestive heart failure, Hypertension, Age $>75$, Diabetes mellitus, and prior Stroke or transient ischemic attack (CHADS2) risk stratification scheme. Am Heart J 2008;156(01):57-64

25 Schotten U, Verheule S, Kirchhof P, Goette A. Pathophysiological mechanisms of atrial fibrillation: a translational appraisal. Physiol Rev 2011;91(01):265-325

26 Wakilli R, Voigt N, Kaab S, Dobrev D, Nattel S. Recent advances in the molecular pathophysiology of atrial fibrillation. Clin Invest 2011;121:2955-2968

27 Katz AM. Proliferative signaling and disease progression in heart failure. Circ J 2002;66(03):225-231

28 Frazier K, Williams S, Kothapalli D, Klapper H, Grotendorst GR. Stimulation of fibroblast cell growth, matrix production, and granulation tissue formation by connective tissue growth factor. J Invest Dermatol 1996;107(03):404-411

29 Twigg SM, Cao Z, MCLennan SV, et al. Renal connective tissue growth factor induction in experimental diabetes is prevented by aminoguanidine. Endocrinology 2002;143(12):4907-4915
30 Mazurek T, Kiliszek M, Kobylecka M, et al. Relation of proinflammatory activity of epicardial adipose tissue to the occurrence of atrial fibrillation. Am J Cardiol 2014;113(09):1505-1508

31 Burstein B, Comtois P, Michael G, et al. Changes in connexin expression and the atrial fibrillation substrate in congestive heart failure. Circ Res 2009;105(12):1213-1222

32 Yue L, Xie J, Nattel S. Molecular determinants of cardiac fibroblast electrical function and therapeutic implications for atrial fibrillation. Cardiovasc Res 2011;89(04):744-753

33 Nattel S, Burstein B, Dobrev D. Atrial remodeling and atrial fibrillation: mechanisms and implications. Circ Arrhythm Electrophysiol 2008;1(01):62-73

34 Li D, Shinagawa K, Pang L, et al. Effects of angiotensin-converting enzyme inhibition on the development of the atrial fibrillation substrate in dogs with ventricular tachypacing-induced congestive heart failure. Circulation 2001;104(21):2608-2614

35 Shiroshita-Takeshita A, Brundel BJ, Burstein B, et al. Effects of simvastatin on the development of the atrial fibrillation substrate in dogs with congestive heart failure. Cardiovasc Res 2007; 74(01):75-84

36 Abed HS, Wittert GA, Leong DP, et al. Effect of weight reduction and cardiometabolic risk factor management on symptom burden and severity in patients with atrial fibrillation: a randomized clinical trial. JAMA 2013;310(19):2050-2060

37 John B, Stiles MK, Kuklik P, et al. Reverse remodeling of the atria after treatment of chronic stretch in humans: implications for the atrial fibrillation substrate. J Am Coll Cardiol 2010;55(12): $1217-1226$

38 Krahn AD, Manfreda J, Tate RB, Mathewson FA, Cuddy TE. The natural history of atrial fibrillation: incidence, risk factors, and prognosis in the Manitoba Follow-Up Study. Am J Med 1995;98 (05):476-484

39 Haïssaguerre M, Jaïs P, Shah DC, et al. Spontaneous initiation of atrial fibrillation by ectopic beats originating in the pulmonary veins. N Engl J Med 1998;339(10):659-666

40 Gelband H, Bush HL, Rosen MR, Myerburg RJ, Hoffman BF. Electrophysiologic properties of isolated preparations of human atrial myocardium. Circ Res 1972;30(03):293-300

41 Prasad K. Transmembrane potential and force of contraction of the normal and potassium-deficient human atrial tissue in vitro. Can J Physiol Pharmacol 1969;47(12):1015-1024

42 Johnson JN, Tester DJ, Perry J, Salisbury BA, Reed CR, Ackerman MJ. Prevalence of early-onset atrial fibrillation in congenital long QT syndrome. Heart Rhythm 2008;5(05):704-709

43 Iwasaki Y-K, Nishida K, Kato T, Nattel S. Atrial fibrillation pathophysiology: implications for management. Circulation 2011;124(20):2264-2274

44 Dobrev D, Voigt N, Wehrens XH. The ryanodine receptor channel as a molecular motif in atrial fibrillation: pathophysiological and therapeutic implications. Cardiovasc Res 2011;89(04):734-743

45 Nattel S. New ideas about atrial fibrillation 50 years on. Nature 2002;415(6868):219-226

46 Bucala R, Cerami A. Advanced glycosylation: chemistry, biology, and implications for diabetes and aging. Adv Pharmacol 1992; 23:1-34

47 Thorpe SR, Baynes JW. Maillard reaction products in tissue proteins: new products and new perspectives. Amino Acids 2003;25(3-4):275-281

48 Kalea AZ, Schmidt AM, Hudson BI. RAGE: a novel biological and genetic marker for vascular disease. Clin Sci (Lond) 2009;116 (08):621-637

49 Yonekura H, Yamamoto Y, Sakurai S, et al. Novel splice variants of the receptor for advanced glycation end-products expressed in human vascular endothelial cells and pericytes, and their putative roles in diabetes-induced vascular injury. Biochem J 2003; 370(Pt 3):1097-1109

50 Sell DR, Monnier VM. Molecular basis of arterial stiffening: role of glycation - a mini-review. Gerontology 2012;58(03):227-237 
51 Wautier MP, Chappey O, Corda S, Stern DM, Schmidt AM, Wautier JL. Activation of NADPH oxidase by AGE links oxidant stress to altered gene expression via RAGE. Am J Physiol Endocrinol Metab 2001;280(05):E685-E694

52 Gloire G, Legrand-Poels S, Piette J. NF-kappaB activation by reactive oxygen species: fifteen years later. Biochem Pharmacol 2006;72(11):1493-1505

53 Reznikov LL, Waksman J, Azam T, et al. Effect of advanced glycation end products on endotoxin-induced TNF-alpha, IL1 beta and IL-8 in human peripheral blood mononuclear cells. Clin Nephrol 2004;61(05):324-336

54 Stassen M, Müller C, Arnold M, et al. IL-9 and IL-13 production by activated mast cells is strongly enhanced in the presence of lipopolysaccharide: NF-K B is decisively involved in the expression of IL-9. J Immunol 2001;166(07):4391-4398

55 Mohammed AM, Syeda K, Hadden T, Kowluru A. Upregulation of phagocyte-like NADPH oxidase by cytokines in pancreatic betacells: attenuation of oxidative and nitrosative stress by 2-bromopalmitate. Biochem Pharmacol 2013;85(01):109-114

56 Yang D, Elner SG, Bian ZM, Till GO, Petty HR, Elner VM. Proinflammatory cytokines increase reactive oxygen species through mitochondria and NADPH oxidase in cultured RPE cells. Exp Eye Res 2007;85(04):462-472

57 Tam XH, Shiu SW, Leng L, Bucala R, Betteridge DJ, Tan KC. Enhanced expression of receptor for advanced glycation endproducts is associated with low circulating soluble isoforms of the receptor in Type 2 diabetes. Clin Sci (Lond) 2011;120(02): 81-89

58 Koyama H, Shoji T, Yokoyama H, et al. Plasma level of endogenous secretory RAGE is associated with components of the metabolic syndrome and atherosclerosis. Arterioscler Thromb Vasc Biol 2005;25(12):2587-2593

59 Prasad K, Dhar I, Zhou Q Elmoselhi H, Shoker M, Shoker A. AGEs/ SRAGE, a novel risk factor in the pathogenesis of end-stage renal disease. Mol Cell Biochem 2016;423(1-2):105-114

60 Prasad K, Tiwari S. Therapeutic interventions for advanced glycation-end products and its receptor- mediated cardiovascular disease. Curr Pharm Des 2017;23(06):937-943

61 Wendt T, Harja E, Bucciarelli L, et al. RAGE modulates vascular inflammation and atherosclerosis in a murine model of type 2 diabetes. Atherosclerosis 2006;185(01):70-77

62 Kuryata O, Muhammad M, Mytrokhina O. Levels of glycation end products and galacti- 3 in patients with chronic heart failure and atrial fibrillation in dependence on the age and renal function. EUREKA: Health Sciences 2018. Available at: http://eu-jr.eu/ health/article/view/542. Accessed October 25, 2019

63 KatoT, Yamashita T, Sekiguchi A, et al. AGEs-RAGE system mediates atrial structural remodeling in the diabetic rat. J Cardiovasc Electrophysiol 2008;19(04):415-420

64 Yan X, Shen Y, Lu L, Sano M, Fukuda K, Shen W. Decreased endogenous secretory RAGE and increased hsCRP levels in serum are associated with atrial fibrillation in patients undergoing coronary angiography. Int J Cardiol 2013;166(01): 242-245

65 Lancefield TF, Patel SK, Freeman M, et al. The receptor for advanced glycation end products (RAGE) is associated with persistent atrial fibrillation. PLoS One 2016;11(09):e0161715

66 Zhao D, Wang Y, Xu Y. Decreased serum endogenous secretory receptor for advanced glycation endproducts and increased cleaved receptor for advanced glycation endproducts levels in patients with atrial fibrillation. Int J Cardiol 2012;158(03): 471-472

67 Al Rifai M, Schneider ALC, Alonso A, et al. sRAGE, inflammation, and risk of atrial fibrillation: results from the Atherosclerosis Risk in Communities (ARIC) Study. J Diabetes Complications 2015;29(02):180-185

68 Yang PS, Kim TH, Uhm JS, et al. High plasma level of soluble RAGE is independently associated with a low recurrence of atrial fibrillation after catheter ablation in diabetic patient. Europace 2016;18(11):1711-1718

69 Schmidt AM, Hori O, Chen JX, et al. Advanced glycation endproducts interacting with their endothelial receptor induce expression of vascular cell adhesion molecule-1 (VCAM-1) in cultured human endothelial cells and in mice. A potential mechanism for the accelerated vasculopathy of diabetes. J Clin Invest 1995;96(03):1395-1403

70 Tanaka S, Avigad G, Brodsky B, Eikenberry EF. Glycation induces expansion of the molecular packing of collagen. J Mol Biol 1988; 203(02):495-505

71 van Heerebeek L, Hamdani N, Handoko ML, et al. Diastolic stiffness of the failing diabetic heart: importance of fibrosis, advanced glycation end products, and myocyte resting tension. Circulation 2008;117(01):43-51

72 Grotendorst GR. Connective tissue growth factor: a mediator of TGF-beta action on fibroblasts. Cytokine Growth Factor Rev 1997;8(03):171-179

73 Park IS, Kiyomoto H, Abboud SL, Abboud HE. Expression of transforming growth factor-beta and type IV collagen in early streptozotocin-induced diabetes. Diabetes 1997;46(03): 473-480

74 Riser BL, Denichilo M, Cortes P, et al. Regulation of connective tissue growth factor activity in cultured rat mesangial cells and its expression in experimental diabetic glomerulosclerosis. J Am Soc Nephrol 2000;11(01):25-38

75 Zhou G, Li C, Cai L. Advanced glycation end-products induce connective tissue growth factor-mediated renal fibrosis predominantly through transforming growth factor $\beta$-independent pathway. Am J Pathol 2004;165(06):2033-2043

76 Li YY, Feng YQ Kadokami T, et al. Myocardial extracellular matrix remodeling in transgenic mice overexpressing tumor necrosis factor alpha can be modulated by anti-tumor necrosis factor alpha therapy. Proc Natl Acad Sci U S A 2000;97(23): 12746-12751

77 Park S-K, Kim J, Seomun Y, et al. Hydrogen peroxide is a novel inducer of connective tissue growth factor. Biochem Biophys Res Commun 2001;284(04):966-971

78 Richter K, Kietzmann T. Reactive oxygen species and fibrosis: further evidence of a significant liaison. Cell Tissue Res 2016;365 (03):591-605

79 Hecker L, Vittal R, Jones T, et al. NADPH oxidase-4 mediates myofibroblast activation and fibrogenic responses to lung injury. Nat Med 2009;15(09):1077-1081

80 Liew R, Khairunnisa K, Gu Y, et al. Role of tumor necrosis factor- $\alpha$ in the pathogenesis of atrial fibrosis and development of an arrhythmogenic substrate. Circ J 2013;77(05):1171-1179

81 Willeit K, Pechlaner R, Willeit P, et al. Association between vascular cell adhesion molecule 1 and atrial fibrillation. JAMA Cardiol 2017;2(05):516-523

82 Verdejo H, Roldan J, Garcia L, et al. Systemic vascular cell adhesion molecule- 1 predicts the occurrence of post-operative atrial fibrillation. Int J Cardiol 2011;150(03):270-276

83 Ono N, Hayashi H, Kawase A, et al. Spontaneous atrial fibrillation initiated by triggered activity near the pulmonary veins in aged rats subjected to glycolytic inhibition. Am J Physiol Heart Circ Physiol 2007;292(01):H639-H648

84 Cortassa S, Aon MA, Marbán E, Winslow RL, O’Rourke B. An integrated model of cardiac mitochondrial energy metabolism and calcium dynamics. Biophys J 2003;84(04):2734-2755

$85 \mathrm{Li} \mathrm{D}$, Fareh S, Leung TK, Nattel S. Promotion of atrial fibrillation by heart failure in dogs: atrial remodeling of a different sort. Circulation 1999;100(01):87-95

86 Derakhchan K, Li D, Courtemanche M, et al. Method for simultaneous epicardial and endocardial mapping of in vivo canine heart: application to atrial conduction properties and arrhythmia mechanisms. J Cardiovasc Electrophysiol 2001;12(05): 548-555 
87 Thomas GP, Sims SM, Cook MA, Karmazyn M. Hydrogen peroxide-induced stimulation of L-type calcium current in guinea pig ventricular myocytes and its inhibition by adenosine $\mathrm{A} 1$ receptor activation. J Pharmacol Exp Ther 1998;286(03):1208-1214

88 Song Y, Shryock JC, Wagner S, Maier LS, Belardinelli L. Blocking late sodium current reduces hydrogen peroxide-induced arrhythmogenic activity and contractile dysfunction. J Pharmacol Exp Ther 2006;318(01):214-222

89 Murrell GA, Francis MJ, Bromley L. Modulation of fibroblast proliferation by oxygen free radicals. Biochem J 1990;265(03): 659-665

90 Lee SH, Chen YC, Chen YJ, et al. Tumor necrosis factor- $\alpha$ alters calcium handling and increases arrhythmogenesis of pulmonary vein cardiomyocytes. Life Sci 2007;80(19):1806-1815

91 Saba S, Janczewski AM, Baker LC, et al. Atrial contractile dysfunction, fibrosis, and arrhythmias in a mouse model of cardiomyopathy secondary to cardiac-specific overexpression of tumor necrosis factor- $\alpha$. Am J Physiol Heart Circ Physiol 2005;289(04):H1456-H1467

92 Musa H, Kaur K, O'Connell R, et al. Inhibition of platelet-derived growth factor- $A B$ signaling prevents electromechanical remodeling of adult atrial myocytes that contact myofibroblasts. Heart Rhythm 2013;10(07):1044-1051

93 Ishii Y, Schuessler RB, Gaynor SL, et al. Inflammation of atrium after cardiac surgery is associated with inhomogeneity of atrial conduction and atrial fibrillation. Circulation 2005;111(22): 2881-2888

94 Choi EK, Chang PC, Lee YS, et al. Triggered firing and atrial fibrillation in transgenic mice with selective atrial fibrosis induced by overexpression of TGF- $\beta 1$. Circ J 2012;76(06):1354-1362

95 Prasad K. AGE-RAGE stress: a changing landscape in pathology and treatment of Alzheimer's disease. Mol Cell Biochem 2019; 459(1-2):95-112

96 Prasad K, Mishra M. Do advanced glycation end products and its receptor play a role in pathophysiology of hypertension. Int J Angiol 2017;26(01):1-11

97 TransTech Pharma LLC; 2014. Available at: http://bciq,biocentury. com/companies/transtech.pharma_inc. Accessed March 10, 2014

98 Sabbagh MN, Agro A, Bell J, Aisen PS, Schweizer E, Galasko D. PF04494700, an oral inhibitor of receptor for advanced glycation end products (RAGE), in Alzheimer disease. Alzheimer Dis Assoc Disord 2011;25(03):206-212

99 Park L, Raman KG, Lee KJ, et al. Suppression of accelerated diabetic atherosclerosis by the soluble receptor for advanced glycation endproducts. Nat Med 1998;4(09):1025-1031

100 Sakaguchi T, Yan SF, Yan SD, et al. Central role of RAGE-dependent neointimal expansion in arterial restenosis. J Clin Invest 2003;111(07):959-972

101 Wautier JL, Zoukourian C, Chappey O, et al. Receptor-mediated endothelial cell dysfunction in diabetic vasculopathy. Soluble receptor for advanced glycation end products blocks hyperpermeability in diabetic rats. J Clin Invest 1996;97(01):238-243

102 Yan SF, Ramasamy R, Schmidt AM. Soluble RAGE: therapy and biomarker in unraveling the RAGE axis in chronic disease and aging. Biochem Pharmacol 2010;79(10):1379-1386

103 Han SH, Kim YH, Mook-Jung I. RAGE: the beneficial and deleterious effects by diverse mechanisms of actions. Mol Cells 2011;31 (02):91-97

104 Youn J-Y, Zhang J, Zhang Y, et al. Oxidative stress in atrial fibrillation: an emerging role of NADPH oxidase. J Mol Cell Cardiol 2013;62:72-79

105 Carnes CA, Chung MK, Nakayama T, et al. Ascorbate attenuates atrial pacing-induced peroxynitrite formation and electrical remodeling and decreases the incidence of postoperative atrial fibrillation. Circ Res 2001;89(06):E32-E38

106 Shiroshita-Takeshita A, Schram G, Lavoie J, Nattel S. Effect of simvastatin and antioxidant vitamins on atrial fibrillation promotion by atrial-tachycardia remodeling in dogs. Circulation 2004;110(16):2313-2319

107 Khabchabov R, Khabchabov RG, Makhmudova ER. Antiarrhythmic effect of antioxidants in patients with atrial fibrillation. J Atr Fibrillation 2016;8(06):1360

108 Costanzo S, De Curtis A, di Niro V, et al; Polyphemus Observational Study Investigators. Postoperative atrial fibrillation and total dietary antioxidant capacity in patients undergoing cardiac surgery: the Polyphemus Observational Study. J Thorac Cardiovasc Surg 2015;149(04):1175-82.e1

109 Rodrigo R, Vinay J, Castillo R, et al. Use of vitamins C and E as a prophylactic therapy to prevent postoperative atrial fibrillation. Int J Cardiol 2010;138(03):221-228

110 Liu T, Li G. Antioxidant interventions as novel preventive strategies for postoperative atrial fibrillation. Int J Cardiol 2010;145 (01):140-142

111 Harling L, Rasoli S, Vecht JA, Ashrafian H, Kourliouros A, Athanasiou T. Do antioxidant vitamins have an anti-arrhythmic effect following cardiac surgery? A meta-analysis of randomised controlled trials. Heart 2011;97(20):1636-1642

112 Rasoli S, Kakouros N, Harling L, et al. Antioxidant vitamins in the prevention of atrial fibrillation: what is the evidence? Cardiol Res Pract 2011;2011:164078

113 Prasad K. Low levels of serum soluble receptors for advanced glycation end products, biomarkers for disease state: myth or reality. Int J Angiol 2014;23(01):11-16

114 Tan KCB, Shiu SWM, Chow WS, Leng L, Bucala R, Betteridge DJ. Association between serum levels of soluble receptor for advanced glycation end products and circulating advanced glycation end products in type 2 diabetes. Diabetologia 2006;49 (11):2756-2762

115 Prasad K, Mishra M. AGE-RAGE stress, stressors, and antistressors in health and disease. Int J Angiol 2018;27(01):1-12 